\title{
Infrared Camera Analysis of Laser Hardening
}

\author{
J. Tesar, P. Vacikova, O. Soukup, and S. Houdkova \\ New Technologies-Research Centre, University of West Bohemia, Univerzitni 8, 30614 Plzeň, Czech Republic \\ Correspondence should be addressed to J. Tesar, tesar@ntc.zcu.cz
}

Received 10 August 2012; Accepted 5 November 2012

Academic Editor: Antoni Rogalski

Copyright () 2012 J. Tesar et al. This is an open access article distributed under the Creative Commons Attribution License, which permits unrestricted use, distribution, and reproduction in any medium, provided the original work is properly cited.

\begin{abstract}
The improvement of surface properties such as laser hardening becomes very important in present manufacturing. Resulting laser hardening depth and surface hardness can be affected by changes in optical properties of material surface, that is, by absorptivity that gives the ratio between absorbed energy and incident laser energy. The surface changes on tested sample of steel block were made by engraving laser with different scanning velocity and repetition frequency. During the laser hardening the process was observed by infrared (IR) camera system that measures infrared radiation from the heated sample and depicts it in a form of temperature field. The images from the IR camera of the sample are shown, and maximal temperatures of all engraved areas are evaluated and compared. The surface hardness was measured, and the hardening depth was estimated from the measured hardness profile in the sample cross-section. The correlation between reached temperature, surface hardness, and hardening depth is shown. The highest and the lowest temperatures correspond to the lowest/highest hardness and the highest/lowest hardening depth.
\end{abstract}

\section{Introduction}

Laser hardening is one of the modern possibilities of improving surface properties of the metallic materials. It is a characteristic of the laser surface hardening process that the material is rapidly heated to a high temperature by guiding the laser beam across the workpiece surface. Short times of interaction between the laser beam and the workpiece surface cause that the absorbed energy is concentrated only at the workpiece surface, whereas the core remains cold. The removal of heat from the surface layer to the colder unaffected metal of a machine part permits rapid cooling and formation of a hardened microstructure required at the workpiece surface.

Parts of hardened surface can be manufactured separately each with different final properties. The final hardness and hardening depth depend primarily on the beam irradiance on the surface of the workpiece, the processing rate, and the thermophysical properties of the material. A low interaction time and a high power result in a shallow hardening depth whereas the converse results in a deeper hardening depth [1]. The parameter that can affect the final properties is the amount of energy accepted from the incident laser beam. This can be changed by corrections of optical properties of the surface absorptivity. The influence of different types of absorbing coatings on specimen surfaces and measurement of IR radiation with a photodiode was presented in [2]. The depth of hardening with and without different coatings was compared in [3]; the connection between surface temperature and absorptivity was emphasized. An infrared camera was used in [4] for process characterization, control, and temperature field monitoring.

An infrared camera ThermaCAM SC3000 was used in [5] for temperature fields measurements during hardening of a cylinder rotating under a laser beam $\left(\mathrm{CO}_{2}, 1.5 \mathrm{~kW}\right.$, $10.6 \mu \mathrm{m})$. The view of the camera was under angle of $30^{\circ}$ from the laser beam. The emissivity was set to the value of 0.88 , corresponding to the applied surface coating, which was used to improve absorptivity.

The same camera but under angle of $53^{\circ}$ from the laser beam of direct diode laser (Nuvonix ISL-4000L, $4 \mathrm{~kW}$, and $805 \mathrm{~nm}$ ) was used in [6]. The emissivity of the sample was estimated during the heating with the propane torch in order to see how emissivity changes with temperature.

In this work an engraving laser is used to obtain surfaces with different optical properties that depend on the parameters of the engraving laser-its wavelength, energy, repetition frequency, and scanning velocity (velocity of laser 
moving). The emissivity for the IR camera measurement is estimated after experiment from an image of infrared camera (thermogram) of the sample that is heated on a hot plate.

The aim of this work is to demonstrate that due to different parameters of engraving laser (repetition frequency and scanning velocity) are reached different surface temperatures by laser hardening caused by different absorptivity on engraved surfaces. The surface temperature has a direct connection with hardening depth and hardness distribution $[2,3,5]$. This way is possible to control surface hardness and hardening depth without change of hardening laser power, for example, for precise hardening of small details on the processed surface.

\section{Theoretical Assumptions}

Incident, reflected, absorbed, and transmitted fluxes are connected together by energy conservation law. From this fact can be deduced that the sum of optical properties reflectivity $(\rho)$, absorptivity $(\alpha)$, and transmissivity $(\tau)$ equals one [7]:

$$
\rho+\alpha+\tau=1
$$

For an opaque object without transmission $(\tau=0)$ the relation (1) simplifies

$$
\rho+\alpha=1
$$

Kirchhoff's law provides a link between the absorption and emission processes and thus between emissivity and absorptivity

$$
\varepsilon=\alpha
$$

These relations are valid for similar spectral or total spectral condition.

In this case there are three sets of optical properties (three different wavelengths) for that Kirchhoff's law is valid. The three wavelengths are wavelength of engraving laser $1064 \mathrm{~nm}$, wavelength of hardening laser $808 \mathrm{~nm}$, and the range of infrared camera $7.5-13 \mu \mathrm{m}$. This means that, for example, emissivity of surface in range of infrared camera $\varepsilon_{I R}$ has no direct connection with absorptivity on wavelength of hardening laser $\alpha_{\mathrm{HPDD}}$.

\section{Experimental Settings}

The investigated sample is a block of steel $95 \mathrm{MnWCr} 5$ of dimensions $105 \times 65 \times 15 \mathrm{~mm}$ with 30 squares of size $5 \times 5 \mathrm{~mm}$ made by laser engraving on the surface of the largest side. The engraving was made with different repetition frequency of laser and scanning velocity. MarkingLaser System BLS-100 (SHT) was used. It contains pulsed $\mathrm{Nd}$ :YAG laser of wavelength $1064 \mathrm{~nm}$. The parameters of engraving make a matrix with repetition frequencies $f$ of 2 , $5,7,15,30$, and $80 \mathrm{kHz}$ and scanning velocities $v$ of 20,50 , 100, 300, and $500 \mathrm{~mm} / \mathrm{s}$ - see Figure 1 .

This sample then undergoes laser hardening with continuous HPDD (high power direct diode) laser HighLight

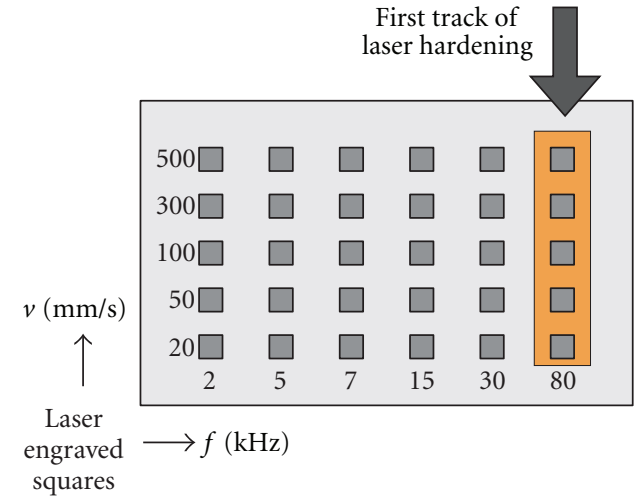

Figure 1: Arrangement of engraved squares on the sample surface.

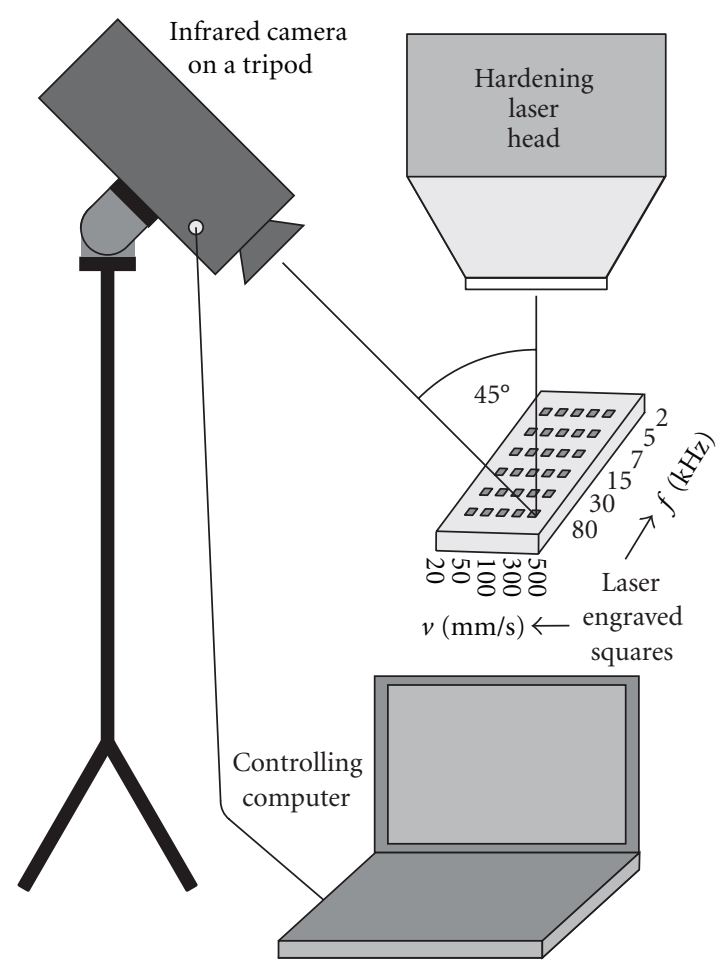

FIGURE 2: Scheme of laser hardening arrangement-laser head on the robotic arm, computer controlled infrared camera on a tripod, and investigated sample.

ISL-4000L (Coherent). The laser working head is placed on the robotic arm (Figure 2, photo on Figure 3). It works on wavelength $808 \pm 10 \mathrm{~nm}$ and the maximal possible power is $4 \mathrm{~kW}$. The laser spot has rectangular shape of dimensions $6 \times 12 \mathrm{~mm}$ with Gaussian energetic profile on the $6 \mathrm{~mm}$ long side and uniform energetic profile on the longer side. The distance between laser head and sample is $12 \mathrm{~cm}$. The laser treating consists of six tracks. The first track begins on square made with highest repetition frequency $(80 \mathrm{kHz})$ and scanning velocity of engraving $(500 \mathrm{~mm} / \mathrm{s})$ and continues with squares of lower scanning velocity-see Figure 1. Next tracks are columns of lower repetition frequencies. 


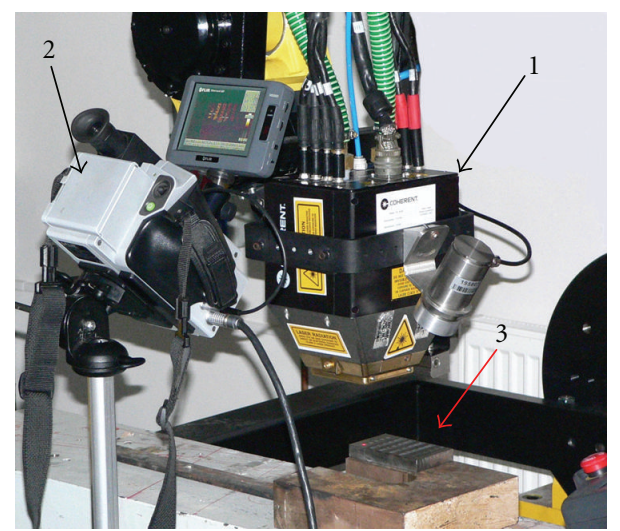

FIgURe 3: Photo of laser hardening arrangement-(1) laser head on the robotic arm, (2) infrared camera, and (3) investigated sample.

The process of laser hardening is measured with computer controlled infrared camera system ThermaCAM SC2000 by company FLIR-photo in Figure 3. It measures emitted infrared radiation in the wavelength range $7.5-13 \mu \mathrm{m}$ and depicts it in a form of temperature field of measured object surface with resolution $320 \times 240$ pixels (uncooled microbolometer FPA detector). The infrared camera has measurement accuracy $\pm 2 \%$, temperature resolution $0.1^{\circ} \mathrm{C}$, and range from $-40^{\circ} \mathrm{C}$ up to $+2000^{\circ} \mathrm{C}$ divided into three regions. The first region, intended for room temperatures, ranges from $-40^{\circ} \mathrm{C}$ to $+120^{\circ} \mathrm{C}$, the middle from $80^{\circ} \mathrm{C}$ to $500^{\circ} \mathrm{C}$ and region for very high temperatures from $350^{\circ} \mathrm{C}$ up to $2000^{\circ} \mathrm{C}$. The camera is placed on a tripod mount and grips with the laser beam angle approximately of $45^{\circ}$. This position is chosen to prevent damaging IR camera by the laser beam reflected from the sample. Another reason is that the laser spot and hot trace are clearly seen and the laser head is not visible in the infrared image.

\section{Measurement}

Each engraved square has a different value of emissivity and these values are not known so the emissivity value of the whole image is set to $\varepsilon=1$ in the infrared camera. Emissivities are set to correct values by postprocessing. The filter (temperature range) from $350^{\circ} \mathrm{C}$ to $2000^{\circ} \mathrm{C}$ is selected. The value of distance between camera and sample is set to $0.5 \mathrm{~m}$ and atmospheric and ambient temperatures to $23^{\circ} \mathrm{C}$. The recording of thermograms (images captured by infrared camera) runs with frequency of $50 \mathrm{~Hz}$. After the end of laser hardening one image is captured with a filter suitable for room temperatures. The treating laser moves with velocity $1200 \mathrm{~mm} / \mathrm{min}$ and works with power of $60 \%$ in the first column $(80 \mathrm{kHz}$ of engraving laser) and with $70 \%$ in other cases. The sample surface after laser hardening of all columns is shown in Figure 4.

After laser hardening the emissivity of all engraved squares was measured using a method of known (constant) temperature. The surface in surroundings of engraved squares was painted with a color of known emissivity and

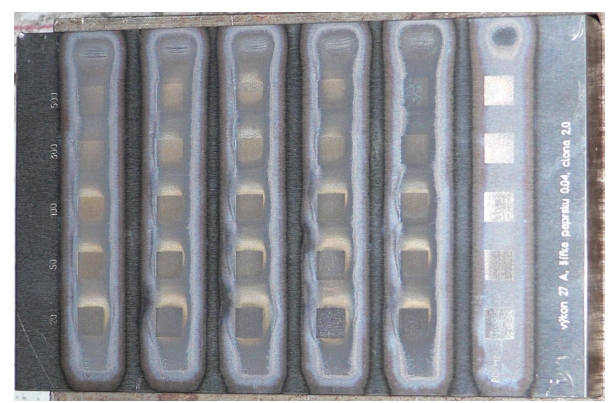

FIgURE 4: The sample surface after laser hardening.

TABle 1: Emissivities of engraved areas in the range of infrared camera $7.5-13 \mu \mathrm{m}$.

\begin{tabular}{lcccccc}
\hline$f(\mathrm{kHz}) / v(\mathrm{~mm} / \mathrm{s})$ & 2 & 5 & 7 & 15 & 30 & 80 \\
\hline 500 & 0.80 & 0.71 & 0.70 & 0.79 & 0.90 & 0.16 \\
300 & 0.75 & 0.71 & 0.75 & 0.73 & 0.86 & 0.21 \\
100 & 0.69 & 0.80 & 0.84 & 0.83 & 0.75 & 0.40 \\
50 & 0.77 & 0.82 & 0.85 & 0.88 & 0.80 & 0.60 \\
20 & 0.85 & 0.89 & 0.92 & 0.95 & 0.90 & 0.79 \\
\hline
\end{tabular}

the sample was placed on electrically heated plate. After temperature stabilizing $\left(\right.$ at $\left.220^{\circ} \mathrm{C}\right)$ a thermogram was captured and the emissivities of engraved areas were determined from equality of temperatures. This proved that every engraved square has different emissivity strongly dependent on parameters of engraving (Table 1).

The whole sample was cut to 30 pieces according to engraved squares after the determination of emissivity and analyzed on automatic microhardness testing system OmniMet MHT (Buehler). Surface hardness HV10 was analyzed and the hardening depth was determined from the profile of microhardness HV0.3 in the sample cross-section.

\section{Postprocessing}

The infrared images of laser hardening were recorded and saved in the form of sequences and one single IR image of hot sample after laser hardening. All sequences and images were evaluated in software ThermaCAM Researcher. The postprocessing procedure started with the single image that was captured with a filter suitable for room temperatures immediately after the end of laser hardening. The sample remained a little hot so the engraved squares with different emissivities and all details were clearly seen (Figure 5).

It was much easier to place single analyzed points with corresponding emissivities to correct places (into the centre of engraved squares) in this picture than in picture of laser hardening made with filter for high temperatures.

With correctly placed analyzed points were loaded six sequences of laser hardening (Figure 6). Each sequence corresponds to one column (engraving laser repetition frequency) and was evaluated separately.

The temporal dependence of temperatures from these points for the second run of hardening laser $(30 \mathrm{kHz}$ of 


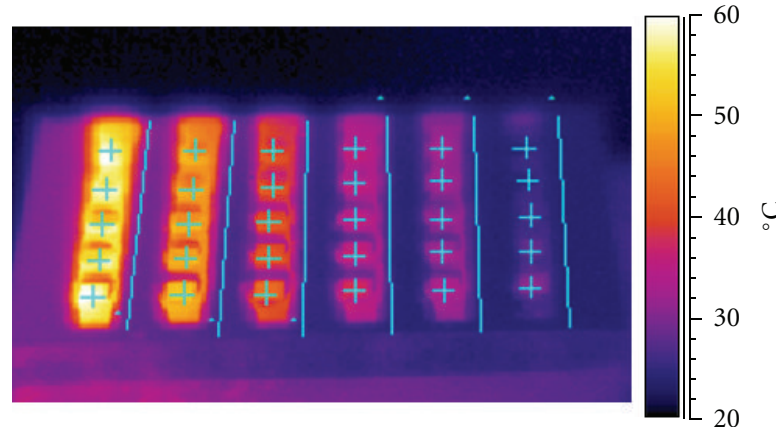

Figure 5: The thermogram of the sample captured with filter for room temperatures immediately after laser hardening.

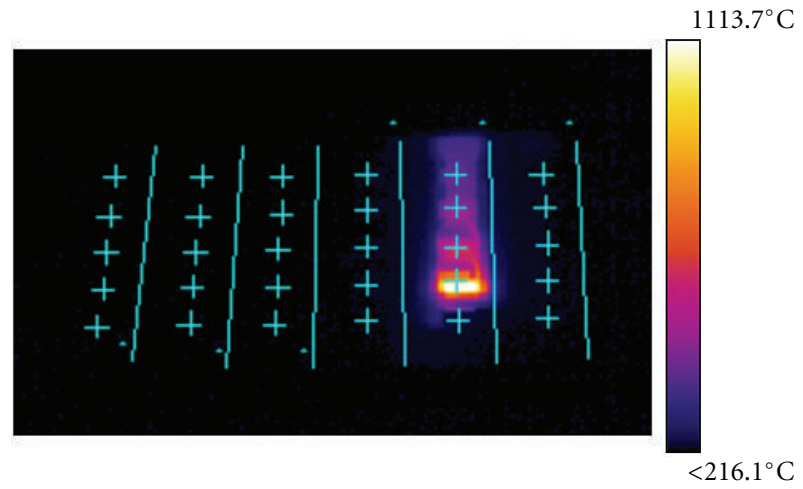

Figure 6: Thermogram of the sample during second track of laser hardening, analyzed points.

engraving laser) is shown in Figure 7. The time consequence of temperature peaks of analyzing points in centers of engraved squares is clearly seen. Each temperature temporal dependence curve begins with increase of temperature then continues short peak and then with an exponential decrease of temperature. The minimum of temperature that can be measured with IR camera using measurement range for region of high temperatures is $215^{\circ} \mathrm{C}$.

From curves of Figure $7(500-50 \mathrm{~mm} / \mathrm{s})$ could be seemed that the maximal values of temperature increase with decreasing emissivity of the engraved squares shown in Table 1. But it is not true. The maximal temperature depends on the amount of absorbed energy brought in the material by hardening laser that is not equal for all squares because of different absorptivity on the wavelength of $808 \mathrm{~nm}$. This absorptivity has no direct connection with emissivity on the wavelength range of infrared camera $7.5-13 \mu \mathrm{m}$.

\section{Results}

In Figure 8 is shown that the maximal temperature $1505^{\circ} \mathrm{C}$ was reached on the square with parameters of engraving laser of $20 \mathrm{~mm} / \mathrm{s}$ and $15 \mathrm{kHz}$ and the lowest temperature $1070^{\circ} \mathrm{C}$ with parameters $500 \mathrm{~mm} / \mathrm{s}$ and $30 \mathrm{kHz}$.

Absolutely the lowest temperature $901{ }^{\circ} \mathrm{C}$ was reached with parameters $300 \mathrm{~mm} / \mathrm{s}$ and $80 \mathrm{kHz}$ but whole this

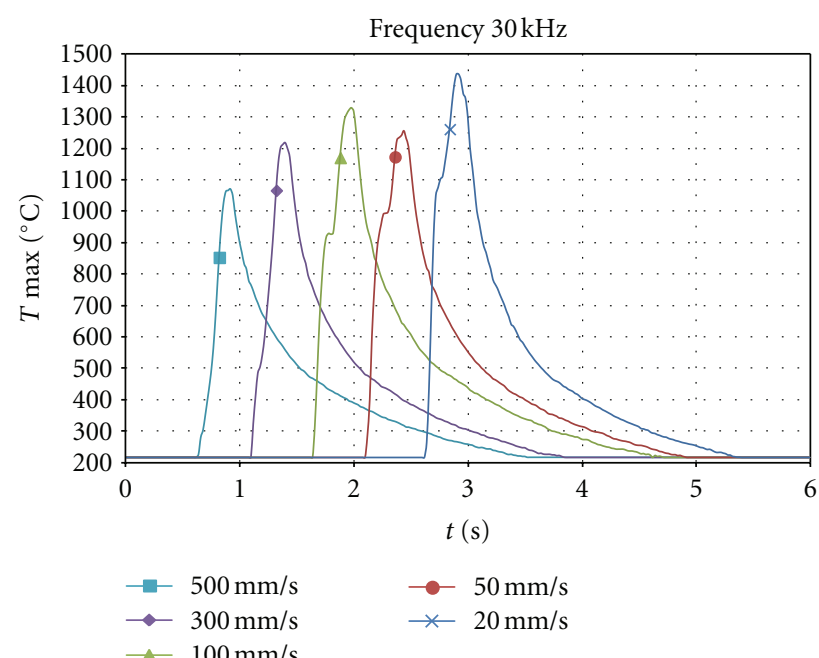

Figure 7: Temporal dependence of maximal temperatures in engraved areas for second run of hardening laser.

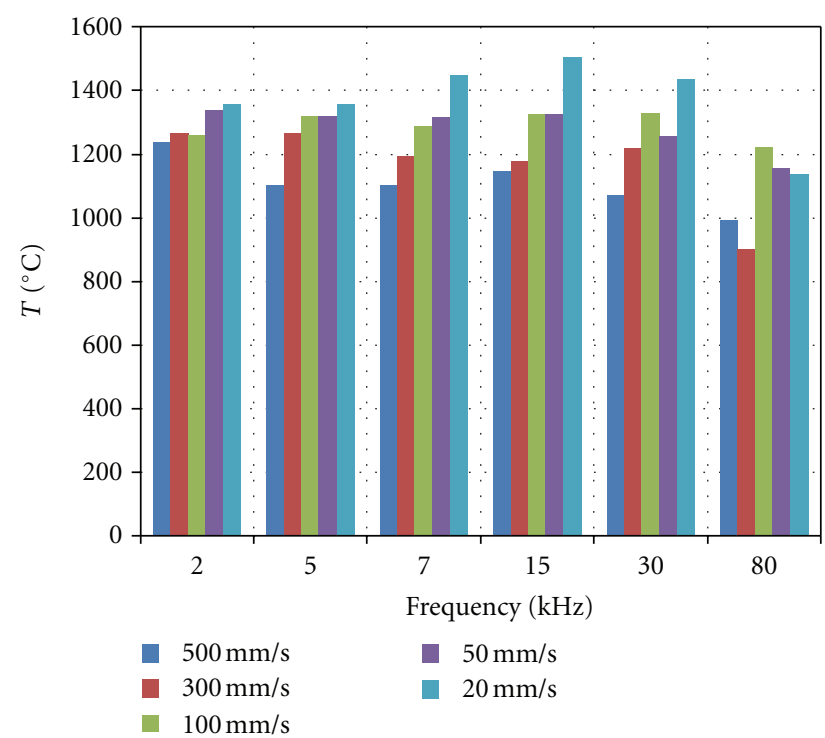

FIGURE 8: Maximal temperatures reached on the engraved squares during run of hardening laser.

column $(80 \mathrm{kHz})$ was made with power of hardening laser $60 \%$ and other columns with power $70 \%$. From Figure 8 it can be also seen that maximal temperature is reached on the squares that were made with the lowest scanning velocity of engraving laser $20 \mathrm{~mm} / \mathrm{s}$ and the minimal temperature on squares made with scanning velocity $500 \mathrm{~mm} / \mathrm{s}$. This is valid with exception of the run of hardening laser with lower power.

The measured surface hardness HV10 and the hardening depth of analyzed squares made with repetition frequency of engraving laser $30 \mathrm{kHz}$ (second track of hardening laser) are depicted in Figure 9. The maximal reached temperatures are written above each column corresponding to the scanning velocity of engraving laser. 


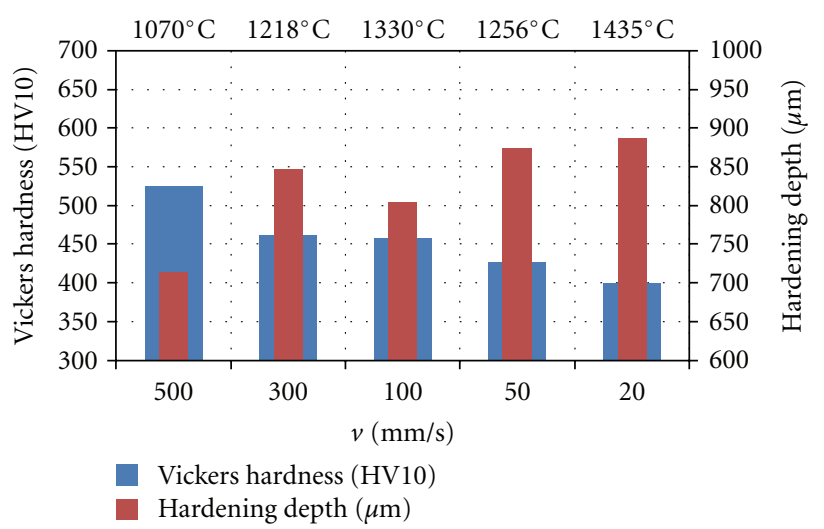

FIGURE 9: The dependence of surface hardness and hardening depth after HPDD laser hardening on scanning velocity of engraving laser by repetition frequency of $30 \mathrm{kHz}$.

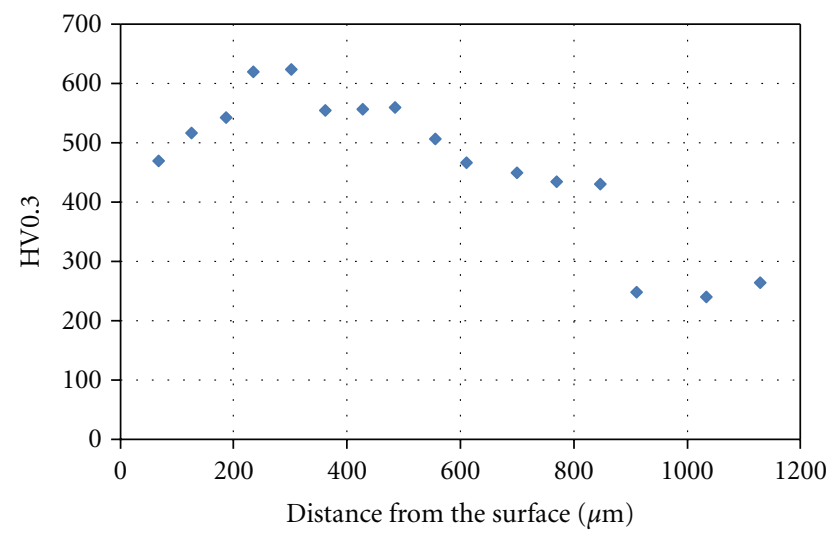

FIGURE 10: The microhardness depth profile on the sample crosssection of the square that was engraved with parameters $30 \mathrm{kHz}$ and $300 \mathrm{~mm} / \mathrm{s}$.

Surface hardness was determined from averaging of five measurements on different places of hardened square surface. The hardening depth was estimated according to big change of hardness values in depth profile (Figure 10) and verified with visual measurement of the sample cross-section on digital microscope Hirox KH-7700 (Hirox) (Figure 11).

The value of hardening depth (square with parameters $30 \mathrm{kHz}$ and $300 \mathrm{~mm} / \mathrm{s}$ ) was estimated to $846 \mu \mathrm{m}$ because in this depth occurred a big decrease of microhardness HV0.3 from value 431 (depth $846 \mu \mathrm{m}$ ) to value 239 (depth $910 \mu \mathrm{m}$ ).

The hardening depth correlates with the reached temperature; higher temperature means bigger depth of hard material $[2,3]$. The results of hardness measurement and measurement of hardening depth in connection with surface temperature measured during laser hardening by infrared camera agree with conclusions stated in $[2,3]$. Exception makes only temperature $1330^{\circ} \mathrm{C}$ (square $100 \mathrm{~mm} / \mathrm{s}$ ) when the Vickers hardness should be lower and hardening depth higher than in case of temperature $1256^{\circ} \mathrm{C}$ (square $50 \mathrm{~mm} / \mathrm{s}$ ) (Figure 12).

The higher surface hardness by lower surface temperatures (Figure 12) is caused by higher cooling rate to bulk

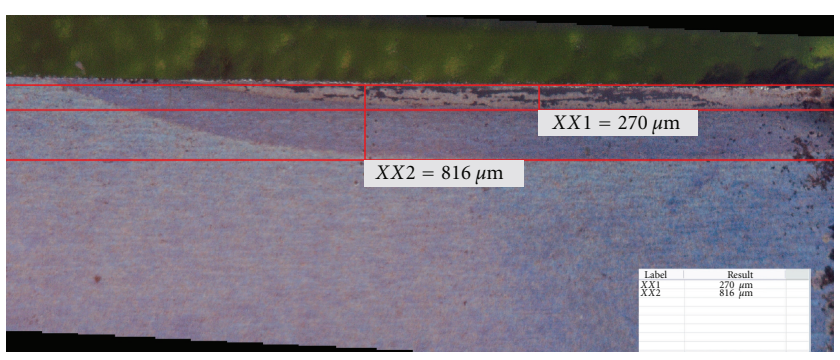

Figure 11: The enlarged picture of the sample cross-section through the square with parameters $30 \mathrm{kHz}$ and $300 \mathrm{~mm} / \mathrm{s}$ made by optical microscope Hirox. There are marked depths of regions with changed structure $(270 \mu \mathrm{m})$ and temperature affected area $(816 \mu \mathrm{m})$.

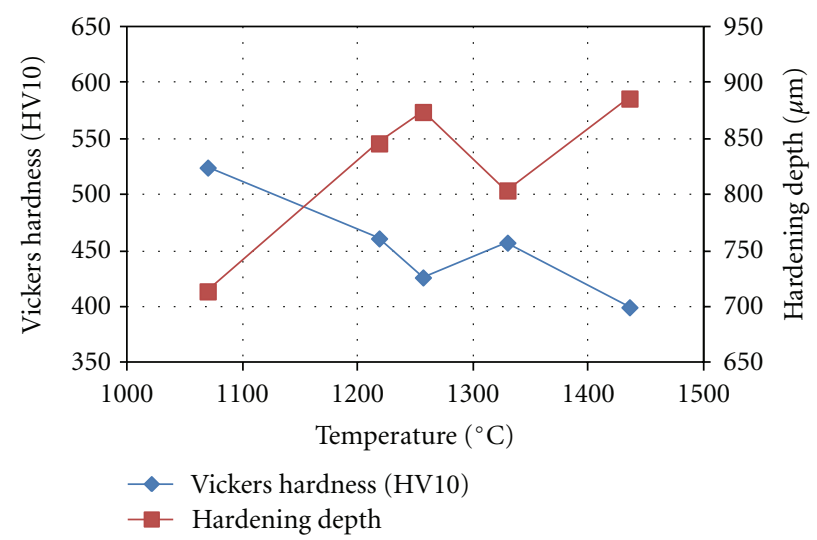

Figure 12: The dependence of surface hardness and hardening depth on the temperature reached on squares made by engraving laser by repetition frequency of $30 \mathrm{kHz}$.

material. The cooling rate by higher surface temperatures is lower because the bulk material has higher temperature in the same depth due to bigger amount of absorbed laser energy. Higher temperature in the depth of material results in higher hardening depth by higher surface temperatures.

\section{Conclusion}

The possibilities of using engraving laser to affect surface absorption of hardening laser were shown in this contribution. The differences in absorptivity cause big differences in surface temperature that is measured with an infrared camera during laser hardening process. Reached surface temperature is directly connected with hardness and hardening depth. Maximal temperatures of all squares are determined and compared together. The result is that the maximal temperature increases with decreasing scanning velocity of engraving laser. The column with repetition frequency of engraving laser $30 \mathrm{kHz}$ was selected for detailed analysis. Hardness and hardening depth estimated from the hardness profile in the sample cross-section were evaluated. The hardening depth was verified by optical microscope. The results prove that the higher surface temperature reached by 
laser hardening means bigger depth of hard material and lower surface hardness.

\section{Acknowledgments}

This paper is based upon work sponsored by the Project no. SGS-2010-083 of the University of West Bohemia in Pilsen. The result was developed within the CENTEM Project, reg. no. CZ.1.05/2.1.00/03.0088, that is cofunded from the ERDF within the OP RDI program of the Ministry of Education, Youth and Sports of Czech Republic. The authors of the paper do not have a direct financial relation with the mentioned commercial identities.

\section{References}

[1] E. Kennedy, G. Byrne, and D. N. Collins, "A review of the use of high power diode lasers in surface hardening," Journal of Materials Processing Technology, vol. 155-156, no. 1-3, pp. 1855-1860, 2004.

[2] J. Grum and T. Kek, "The influence of different conditions of laser-beam interaction in laser surface hardening of steels," Thin Solid Films, vol. 453-454, pp. 94-99, 2004.

[3] V. S. Kovalenko and D. F. Dauw, "Ways to intensify laser hardening technology," CIRP Annals, vol. 47, no. 1, pp. 133136, 1998.

[4] H. Attia, S. Tavakoli, R. Vargas, and V. Thomson, "Laser-assisted high-speed finish turning of superalloy Inconel 718 under dry conditions," CIRP Annals, vol. 59, no. 1, pp. 83-88, 2010.

[5] R. Patwa and Y. C. Shin, "Predictive modeling of laser hardening of AISI5150H steels," International Journal of Machine Tools and Manufacture, vol. 47, no. 2, pp. 307-320, 2007.

[6] S. Skvarenina and Y. C. Shin, "Predictive modeling and experimental results for laser hardening of AISI 1536 steel with complex geometric features by a high power diode laser," Surface and Coatings Technology, vol. 201, no. 6, pp. 2256-2269, 2006.

[7] X. P. V. Maldague, Theory and Practise of Infrared Technology for Nondestructive Testing, Wiley Interscience, 2001. 

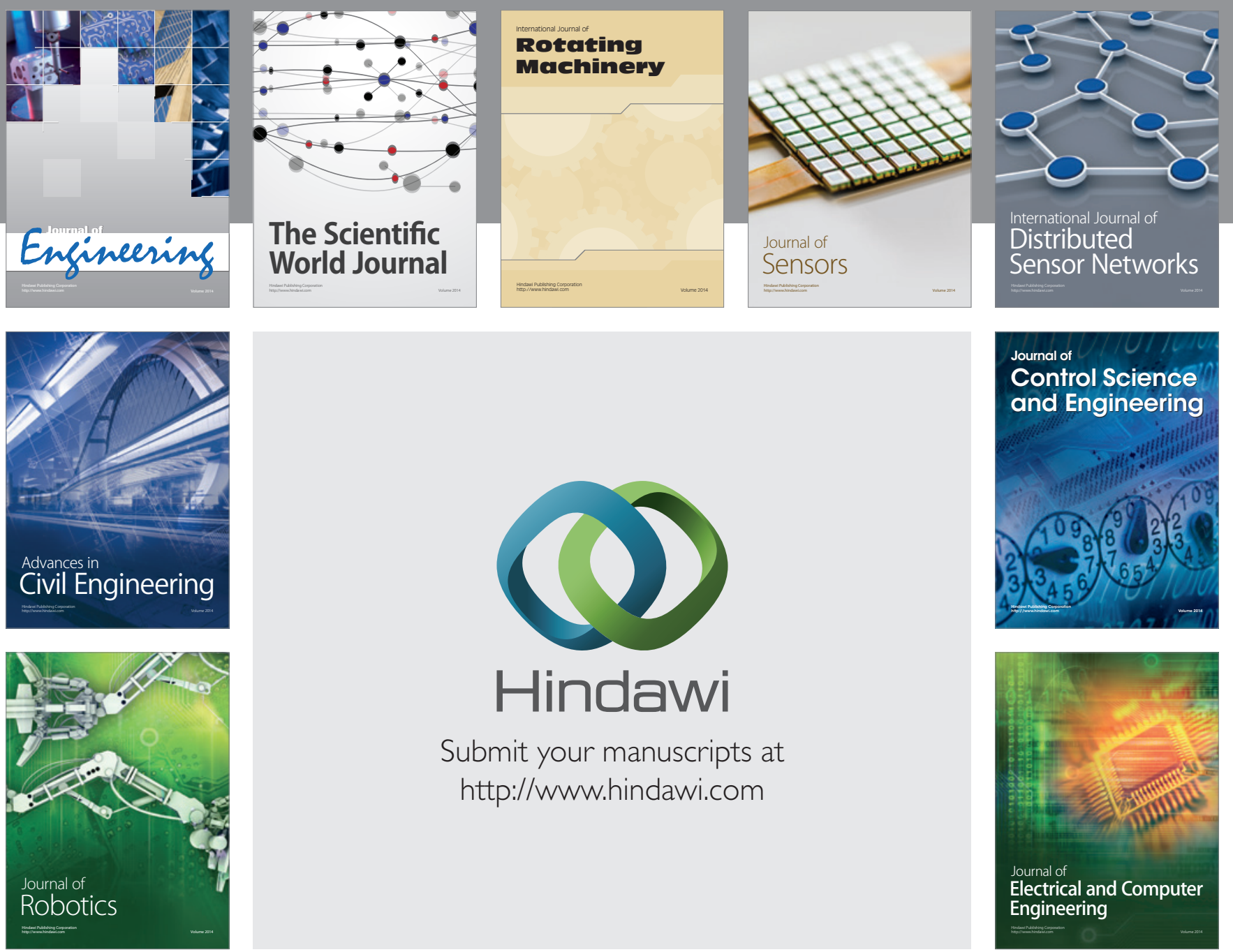

Submit your manuscripts at

http://www.hindawi.com
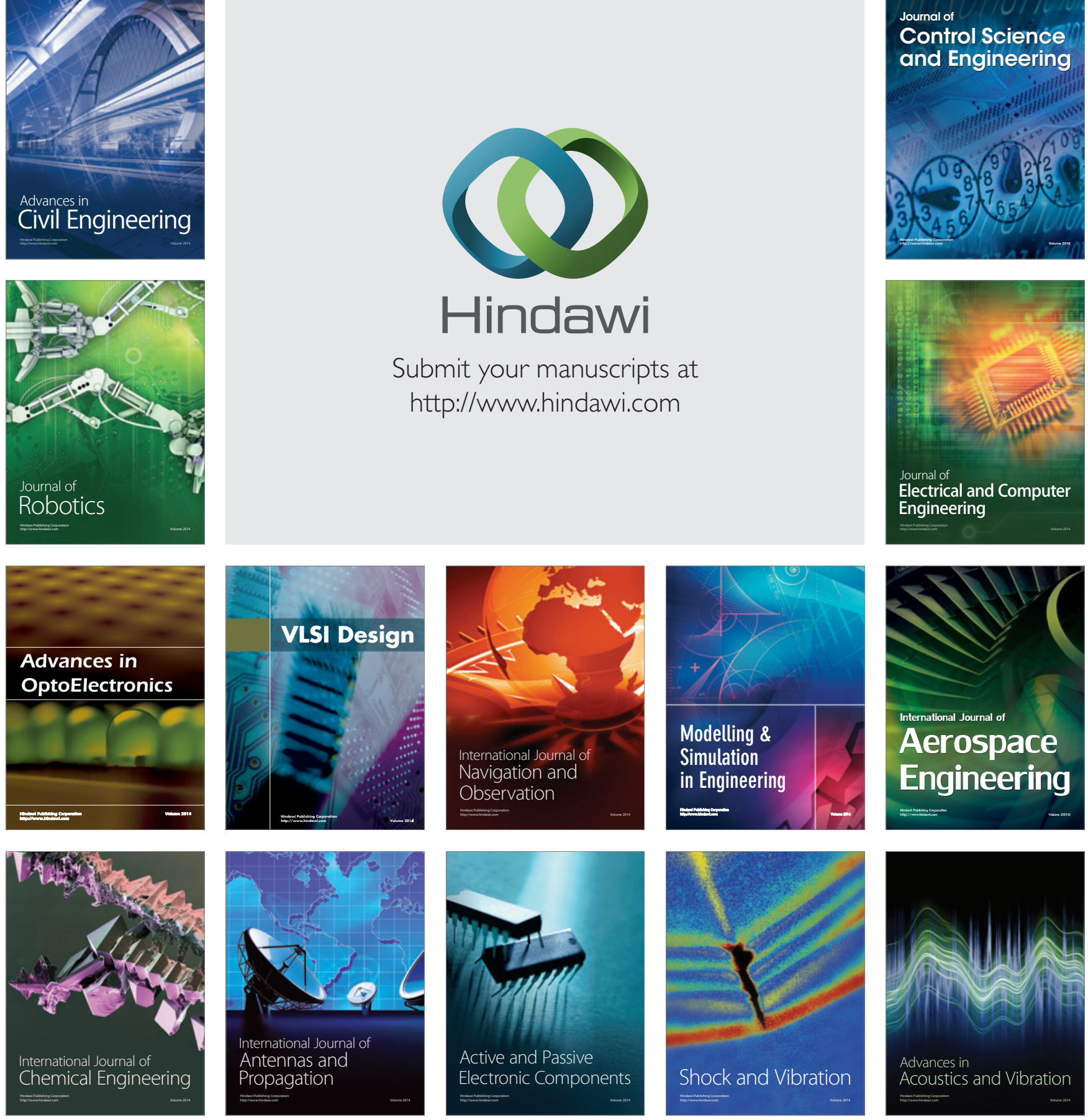